\title{
Ética de la inclusión y personas con discapacidad intelectual
}

\section{The ethics of inclusion and individuals with intellectual disability}

\section{Palabras clave}

Inclusión, exclusión, reconocimiento, identidad, emociones.

\section{Keywords}

Inclusion, exclusion, recognition, identity, emotions.

\begin{abstract}
"Inclusión" es la categoría básica en juego cuando se plantea la tarea social en torno a los derechos y la vida plena de las personas con discapacidad. Por eso es tan importante aclararla desde el punto de vista ético. Pues bien, se descubre qué es de verdad la inclusión - como justicia- percibiendo cómo se nos revela en las víctimas de la exclusión - como injusticia-. Lo que supone que conviene presentar la ética de la inclusión a partir de lo que es la exclusión real, con las víctimas que crea. Aquí se tendrá específicamente presentes a las personas con discapacidad intelectual. Para exponer el tema se asume un modo de presentación esquemático-sintético.
\end{abstract}

\section{Del hecho de la exclusión a la reclamación de la inclusión}

1.1. Explicitemos el panorama o mapa de la exclusión, para hacernos cargo de su alcance y poder orientarnos

- En el excluir hay modos y grados:

a. ignorar a alguien, en la inconsciencia o en la consciencia;

b. prescindir de alguien, en la consciencia del que prescinde;

C. rechazar activamente a alguien, en la iniciativa más frontal.
Xabier Etxeberria <xetxemau@deusto.es>

Universidad de Deusto. España

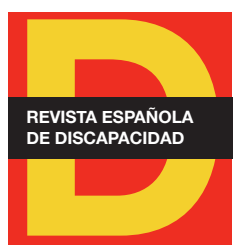

Para citar:

Etxeberria, X. (2018): "Ética de la inclusión y personas con discapacidad intelectual". Revista Española de Discapacidad, 6 (I): 281 290.

Doi: <https://doi.org/10.5569/23405104.06.01.14> 
Observaciones: 1) la inconsciencia no responsable inhibe la culpabilidad personal pero no debe olvidarse que no inhibe la exclusión, que es lo que debe importarnos en primer lugar (sus víctimas); 2) hay que enfrentarse a la potencial ignorancia inconsciente en la que podemos estar.

- Se puede excluir a alguien:

a. para algo para lo que no sería competente y teniendo presentes los derechos de los otros [ej. practicar la medicina];

b. globalmente, como persona, por lo que es a ojos del que excluye [ej. estudiante "rarito" al que se puede acosar].

- Se puede excluir a personas individuales o a colectividades enteras, definidas - por el que excluyepor una identidad determinada que desprecia (y a veces teme). El riesgo de exclusión más crudo lo padece quien reúne varias de esas identidades [ej. persona con discapacidad intelectual-inmigrantemujer-pobre].

- La exclusión puede:

a. responder a iniciativas explícitas: de personas individuales [ejemplos citados] o de responsables institucionales [ej. políticas públicas que no ofrecen los recursos de apoyo que en justicia les corresponden a las personas con discapacidad intelectual];

b. estar insertada en la cultura y las estructuras sociales dominantes, que la "naturalizan" [ej. estaría en la naturaleza de las cosas que las personas con discapacidad intelectual tienen que ser segregadas en la escuela].

Observación: En el segundo caso no podemos acusar a personas concretas de ser excluyentes; con todo, de cara a la exclusión efectiva, es el mecanismo más grave y perversamente "eficaz" y el más complicado de transformar.

\subsection{Criterio de moralidad}

- La exclusión es moralmente indebida (daño injusto), en todas sus variables, cuando se excluye a quien no debe ser excluido y por lo que no debe ser excluido; esto es, cuando la exclusión hiere, por acción o por omisión, la dignidad universal de alguien. La exclusión de la persona como tal siempre la hiere de este modo. En lo que sigue, me remito a esta exclusión inmoral ejercida contra las personas con discapacidad intelectual.

\subsection{La inclusión como reverso ético de la exclusión}

- Hablamos, por contraposición, de sociedad inclusiva para referirnos a una sociedad en la que:

a. sus culturas y sus estructuras relevantes (sanidad, trabajo, participación política, etc.) ni expresan ni realizan exclusiones moralmente indebidas [piénsese en concreto en la educación inclusiva, también de personas con discapacidad intelectual];

b. sino que, al revés, ofrecen apoyos a las personas en la medida en que los necesitan para que su inclusión pueda ser plena; 
c. y en la que se vela eficazmente para que tampoco se den exclusiones en las relaciones intersubjetivas [ej. acoso escolar en la escuela inclusiva].

- Veamos cómo enfoca la inclusión la Convención de 2006. Tanto el análisis de la exclusión de las personas con discapacidad intelectual, como el diseño de la vía hacia su plena inclusión, dependen, en parte, del paradigma de referencia que tengamos para concebir la discapacidad.

a. Se distinguen al menos cuatro: médico-rehabilitador, social, biopsicosocial y de diversidad funcional en sentido fuerte. Del primero debe advertirse que, asumido en su versión estricta, tiene un sustrato excluyente inherente a él, por lo que debe ser rechazado.

b. Respecto a los otros tres, opto por el paradigma biopsicosocial que privilegia la Convención de 2006: la discapacidad es fruto de la interacción de una deficiencia en la persona - que le dificulta realizar algunas funciones valiosas - con la sociedad, en el grado y medida en que esta no es inclusiva (esto es, en medida muy relevante, es discapacitadora la sociedad con sus exclusiones, según se ha visto). De ello se desprende el derecho (que remite a obligaciones) de:

- Crear una sociedad estructural y culturalmente inclusiva con todas las personas, incluidas por tanto las personas con discapacidad intelectual, en la que todos puedan ejercer sus derechos y deberes. La Convención lo expresa así: "diseño de productos, entornos, programas y servicios que puedan utilizar todas las personas, en la mayor medida posible, sin necesidad de adaptación" (art. 2) [Ej. accesibilidad universal, para la movilidad, de un edificio; pero también accesibilidad universal, para la educación, de las escuelas].

- Ofrecer igualdad de oportunidades: hacer todas las transformaciones legislativas, judiciales y administrativas, todas las reconfiguraciones necesarias en servicios clave como los educativos o los sanitarios o los laborales, etc., para que, por un lado, expresen esa igualdad de oportunidades y, por otro, sienten las bases que la hacen posible.

- Ofrecer apoyos y acompañamientos personalizados necesarios para el desarrollo de las capacidades, de la capacidad de autodeterminación en especial [ej. derecho al voto].

- Solo en casos inevitables, tras ofrecer todo lo anterior, realizar: a) acomodos para grupos y situaciones particulares de personas con discapacidad; b) sustituciones en el ejercicio de la autodeterminación [ej. gestión del propio dinero y de los bienes].

Presentada así la concepción básica de la inclusión, continuemos con el objetivo de clarificarla éticamente partiendo del análisis de los mecanismos de exclusión, con la finalidad de ayudar a promoverla socialmente.

\section{Inclusión frente a la exclusión, y reconocimiento}

\subsection{Exclusión y mal reconocimiento}

- Se excluye a alguien a quien se le destaca un rasgo no asignable a su responsabilidad, en nuestro caso, limitación cognitiva, en torno al que se construye un proceso o mecanismo de mal reconocimiento. Se concreta de este modo: 
a. el rasgo en cuestión es considerado negativo, disvalor - no sería persona plena, sería una carga social, etc. - ;

b. lo que le haría no merecedor o incapaz de integrarse normalizadamente en la sociedad;

c. ignorándose la decisiva responsabilidad de la sociedad — como sociedad excluyente - en la interpretación y materialización concreta de ese rasgo [recuérdese la Convención];

d. identificando a la persona en su integridad con el rasgo así percibido [es un discapacitado: las terminologías acaban convirtiéndose en insultos de desprecio; muy diferente a decir "es valenciano"] y, por tanto, excluyéndola como tal;

e. y situándola en el colectivo de quienes comparten el rasgo, esto es, excluyendo al colectivo en su conjunto, identificado igualmente solo con el rasgo prejuiciado.

- $\quad$ En todos estos considerandos:

a. se quebranta el criterio fundamental y universal de respeto a la dignidad de cada persona;

b. hay una errónea lectura de la realidad que, además, oculta la (i)responsabilidad de las estructuras sociales y de los ciudadanos;

c. en definitiva, hay un mal reconocimiento moral de la persona y el colectivo.

- La dinámica presente en ese proceso de exclusión puede llegar a ser la de la estigmatización. Recordemos que:

a. estigma es una marca o señal, física o psíquica o cultural;

b. que tiende a percibirse como indeleble;

c. de la que emana, para el que la concibe así - el estigmatizador - , un desdoro, una afrenta;

d. ante lo que reacciona con el desprecio -o incluso el odio- y la exclusión, históricamente durísimos.

- La que sí está presente siempre en las dinámicas excluyentes es la discriminación, la del trato desigual, inferiorizador, al grupo mal reconocido, en lo que tiene que ver con los derechos y los criterios de justicia: se considera que deben ser disfrutados en plenitud únicamente por los plenamente "integrables" [y las personas con discapacidad intelectual no lo serían].

- El fruto de la discriminación es la marginación.

a. Quien la sufre es situado en los márgenes de la sociedad, en "espacios especiales", que, en nuestro caso, se dice, serían "apropiados a su condición de discapacidad“. Sistematizados y generalizados (lo que tiende a suceder con las personas con discapacidad intelectual), implican vivir separados, como extraños respecto a la sociedad, sin poder disfrutar de múltiples bienes y posibilidades que ofrece la inclusión en todos los espacios de ella.

b. Estos espacios de marginación pueden ser localizados a través de la formulación de esta pregunta en negativo: ¿en dónde no se ve socialmente "normal" que estén presentes, con naturalidad, las personas con discapacidad intelectual, a la manera en que puede estarlo cualquier otra persona que no tenga esta discapacidad? ¿En dónde, espontáneamente, se percibe incómoda o inadecuada su presencia? Aplíquese la pregunta al transporte público, sala de fiestas, mesa de votaciones, escuela, museo, práctica deportiva, mercado, excursiones, servicios de notaría, etc., para ver avances y tareas pendientes. 
- La marginación tiene el efecto perverso de la invisibilización, aunque no funciona de la misma manera en todos los colectivos excluidos. Como en la marginación, unos tienen invisibilización parcial (solo en algunos sectores, por ejemplo, inmigrantes) y otros cuasi general (por ejemplo, personas con discapacidad intelectual).

a. Si las personas con discapacidad no están significativa y habitualmente presentes en las instituciones y los espacios comunes, son invisibles para la mayoría de la población. Esta funciona como si ellas no existieran, como si fueran una remota y confusa realidad, que nos incomoda cuando roza con nosotros en el autobús o en la cafetería.

b. La invisibilización impide que la marginación sea moralmente interpeladora para los ciudadanos, juega a favor de mantener la situación de exclusión. Esto es, se da un círculo perverso de potenciación mutua entre marginación e invisibilización. Es, por eso, una exigencia ética la toma de iniciativas, conjuntamente con las personas afectadas, que supongan la ruptura del muro de la invisibilización, todavía notablemente presente.

\subsection{Inclusión y buen reconocimiento}

- Pues bien, frente a esas dinámicas injustas de mal reconocimiento, el buen reconocimiento moral, el reconocimiento en justicia, es el que se ofrece en formas que contrarrestan y reparan el reconocimiento indebido. En este reconocimiento, y aplicado a nuestro caso, hay dos momentos llamados a imbricarse y realizarse efectivamente:

a. el momento de universalidad: reconocer a toda persona con limitación cognitiva como humano igual que todos los humanos, ni más ni menos, es decir, como sujeto de dignidad y por tanto como valor en sí, frente a su consideración como disvalor o como mero valor instrumental que puede ser utilizado; considerándola de este modo sujeto de todos los derechos, como persona y como ciudadano, que emanan de esa dignidad;

b. el momento de especificidad: el que reacciona ante la negación o penalización de la diversidad, en nuestro caso ligada al rasgo de limitación cognitiva, el reconocimiento del derecho de la persona a los apoyos pertinentes para que disfrute de la igualdad de oportunidades, para que su inclusión social sea lo más plena posible.

Su efectuación imbricada. El reconocimiento real es el que no se queda en palabras, el que se traduce en las transformaciones estructurales, los cambios culturales y los apoyos específicos que lo hacen efectivo. Para ello tienen un papel muy relevante las instituciones públicas, pero se precisa también la implicación del conjunto de la ciudadanía, organizada en lo que sea necesario.

- Este buen reconocimiento no excluyente:

a. depende de los otros, mostrándosenos en ello, a la vez, la solidaridad y vulnerabilidad constitutivas de los humanos, su grandeza y su fragilidad;

b. garantiza las condiciones que precisan todas las personas para orientar sus iniciativas hacia una vida realizada, en la convivencia intersubjetiva y cívica, además de posibilitar la experiencia de la vivencia personal efectiva de ser sujeto de dignidad; 
c. alienta en concreto el autorrespeto, la autoestima y la autoconfianza, tres experiencias personales decisivas para la consistencia personal que, también, son la base necesaria para la creatividad de la autonomía.

\section{Inclusión frente a la exclusión e identidad}

\subsection{Los mecanismos de la exclusión}

- La conexión entre exclusión e identidad es doble:

a. se excluye a los colectivos por razón de su identidad;

b. el mal reconocimiento implicado en la exclusión incide en la construcción de la identidad personal y colectiva de la persona excluida, agrandando su negatividad.

- Respecto a lo primero, se da este proceso:

a. se excluye a quien se considera que no es "de los nuestros";

b. hetero-definiendo su identidad a partir de un rasgo diferente (en nuestro caso, funcionamiento de la capacidad cognitiva) con el que es identificado;

C. rasgo que es valorado como negativo;

d. siendo esta identidad minusvalorada la razón de la exclusión.

Es, pues, una dinámica similar a la del mal reconocimiento ya descrita, pero resaltándose ahora que afecta a algo tan relevante como la identidad personal y colectiva de los excluidos. Por eso conviene insistir.

\subsection{Hacia identidades inclusivas}

- Para nosotros lo que cuenta es la auto-identidad como auto-identificación, pero en ella ocupa un lugar relevante la identificación que nos viene de los otros en la forma de buen o mal reconocimiento. Consideremos para aclararlo los tres ángulos del triángulo interactivo de constitución de la identidad personal y colectiva:

- En la construcción de la identidad interactúan tres ángulos (imagínese un triángulo equilátero en el que cada ángulo, al expandirse, incluye a los otros):

a. el de los enraizamientos culturales en los que somos socializados: relevancia de una socialización rica y abierta a la libertad;

b. el de los reconocimientos que recibimos de los demás, que pueden ser positivos y ajustados o negativos; estos a su vez pueden ser conscientemente negativos o inconscientemente negativos -naturalizados-;

c. el de las iniciativas que tomamos, apoyados en enraizamientos y reconocimientos, pero también críticamente frente a ellos. 
Analícese cómo funcionan estos factores y su articulación en el caso de las personas con discapacidad intelectual: los avances que se han dado, los lastres que quedan, etc.

- El triángulo muestra que construimos nuestra identidad, en una parte importante, interiorizando los hetero-reconocimientos socialmente dominantes y los de los otros significativos para nosotros, hasta el punto de poder hacerlos auto-identificaciones:

a. Si son degradantes, si están acompañados de la exclusión, nos empujan a concebir y vivir personalmente una identidad inferiorizada. Identidad con la que no somos capaces de vivenciar nuestro propio valor en las relaciones con los otros y de la que querríamos deshacernos. Con lo cual nuestra autonomía personal y cívica y nuestras posibilidades de alcanzar una "vida realizada", quedan gravemente heridas.

b. A menos que, en nosotros, con la ayuda de quienes nos apoyan cuando se precise, encontremos fortalezas decisivas para contrarrestar los mal-reconocimientos.

Considérese cómo está funcionando esto, en lo positivo y lo negativo, de cara a las personas con discapacidad intelectual: en general en España, en nuestros lugares concretos.

- Las iniciativas contra la exclusión deben tratar de romper esta dinámica destructiva que, como se ha visto, no es meramente externa al sujeto excluido, pues puede haber anidado en él por la interiorización de una opresión en el reconocimiento, ocultada incluso al propio sujeto excluido a través de su "naturalización" (consistente en considerar que realidades que son como son por iniciativas humanas, lo serían así por naturaleza).

- El buen reconocimiento en el horizonte de la identidad no tiene solo una dimensión receptiva por parte de quien lo recibe (aquí, las personas con discapacidad intelectual). Tiene también una dimensión activa. Se sintetiza recepción y acción en el diálogo en el que nos reconocemos mutuamente, en el que nos relacionamos desde identidades dispuestas a aprender unas de otras y a colaborar. Esta es la mejor expresión de que la exclusión ha sido desterrada.

\section{Inclusión frente a la exclusión y emociones}

- La intensidad con que se experimenta y se vive todo lo que rodea a la exclusión se debe a que no solo están en juego principios y valores morales desde los que discernir qué está mal o bien y qué debe hacerse. Hay también, interactuando, intensas vivencias emocionales.

\subsection{Las emociones en la exclusión}

- Estas vivencias emocionales (cito solo algunas) emergen por diversas causas y en direcciones diferentes e incluso opuestas. Pueden ser estimuladas:

- En quien excluye, por los prejuicios adheridos a las dinámicas excluyentes:

a. soberbia respecto a sí mismo al creerse superior; 
b. menosprecio hacia el excluido considerándolo por naturaleza inferior;

c. "conmiseración" hacia él, si no hay conciencia de que su situación es injusta, con inclinación a la ayuda paternalista [es importante aclarar que la compasión es otra cosa, aunque con frecuencia sea confundida con ella];

d. inocencia respecto a sí mismo al no asignarse responsabilidad por la realidad de la exclusión.

- En quien es excluido [y en las familias], por los mal-reconocimientos y exclusiones sufridas e interiorizadas:

a. vergüenza psicológica de fondo, por percibirse con una identidad "inferior" a la de los demás;

b. con la correspondiente minusvaloración y menosprecio de sí;

c. humillación ante la percepción de conductas de menosprecio de los otros;

d. incluso culpabilidad - la persona con discapacidad o sus familiares - al atribuirse, presionados por el menosprecio, responsabilidad en una discapacidad que tendría un difuso fondo de mal [raíces culturales de ello muy crudas en el pasado].

\subsection{Emociones para la inclusión}

- En quien es excluido o excluida, por la conciencia lúcida de la injusticia de su exclusión:

a. indignación moral ante la injusticia sufrida, con motivación para reivindicar la justicia que se le debe;

b. estima de sí como persona sujeto de dignidad y derechos;

c. autoconfianza lúcida en sus posibilidades;

d. consistencia serena como talante vital de fondo.

- En quien ha excluido, gracias al impacto del excluido, al que "ve como tal" y que, desbaratándole sus prejuicios, hace emerger en él estas emociones:

a. vergüenza moral por las dinámicas excluyentes en las que ha participado o que ha asumido como naturales, con autoasignación de la responsabilidad que le corresponda;

b. humildad en cuanto asentamiento en su verdad ante sí y ante la persona y el colectivo excluidos;

c. respeto empático a estos;

d. indignación moral ante toda injusticia de exclusión que perciba, motivadora del compromiso compartido por suprimirla.

En el entrelazado de los sentimientos positivos de quien ha sido excluido y quien excluyó, aparece el sentimiento de solidaridad compartida, abierto a que se haga solidaridad colaborativa en la acción.

\subsection{Breves comentarios sobre las emociones}

- Las emociones que sentimos:

a. son las que desvelan lo que de verdad el otro es para mí, más allá de lo que digo que es;

b. afectan a la totalidad de las facultades de la persona; 
c. motivan su iniciativa - de acción y de omisión-;

d. cuando funcionan adecuadamente tienen una dimensión cognitiva, nos hacen descubrir ciertas realidades.

Por eso son tan relevantes, por eso es tan importante cultivarlas (pueden ser educadas) en orden a que se expresen en su versión moral y que se arraiguen en nosotros establemente como actitudes o virtudes.

- Ahondando en esto último: la emergencia inicial de la emoción es espontánea, pero puede y debe ser transformada cuando se precise y trabajada - responsabilidad - para que se viva como sentimiento moral, para que exprese y potencie el bien moral, para que sea agente decisivo de la denuncia de la exclusión, de la lucha contra ella, de la inclusión lograda.

- Aplíquese todo esto a la exclusión que sufren las personas con discapacidad intelectual, al modo emocional como ellas la viven, a cómo lo viven sus familias; así como a los procesos de avance hacia modos de vivencias expresivas y realizadoras de inclusión plena. 


\section{Referencias bibliográficas}

Este texto es deudor del poso dejado en su autor por múltiples lecturas como estas:

Camps, V. (2011): El gobierno de las emociones. Barcelona: Herder.

Honneth, A. (2010): Reconocimiento y menosprecio. Sobre la fundamentación normativa de una teoría social. Madrid: Katz.

Marina, J. A. (1998): El laberinto sentimental. Barcelona: Anagrama.

Nussbaum, M. (2015): Paisajes del pensamiento. La inteligencia de las emociones. Barcelona: Paidós.

Renault, E. (2004): L'experience de l'injustice. Reconnaissance et clinique de l'injustice. París: La Découverte.

Ricoeur, P. (2006): Caminos de reconocimiento. México: FCE.

Taylor, C. (1996): "Identidad y reconocimiento". Revista internacional de filosofía política, 7: 10-19.

El texto tiene también conexiones con estas dos obras del autor:

Etxeberria, X. (2012): Virtudes para convivir. Madrid: PPC.

Etxeberria, X. (2008): Por una ética de los sentimientos en el ámbito público. Bilbao: Bakeaz. 